\title{
Organisational synergies, dissonance and spinoffs
}

\author{
Mili Shrivastava* \\ Executive Business Centre, \\ Bournemouth University, \\ 89 Holdenhurst Road, Bournemouth, BH8 8EB, UK \\ E-mail: mshrivastava@bournemouth.ac.uk \\ *Corresponding author
}

\section{T.V.S. Ramamohan Rao \\ Indian Institute of TechnologyKanpur 6-5-45/1 Type 1, Self Finance Colony, Vanastalipuram, Hyderabad 500070, India E-mail:rmrao@iitk.ac.in}

\begin{abstract}
Spinoff firms are a distinct class of new entrants across industries. The causes for their emergence have been widely investigated in the literature. However, the role of team environments has received little attention. On the one hand, talented individuals may find it necessary to team up with others to utilise complementary knowledge and generate synergies. On the other hand, some types of team production environments may exhibit dissonance and motivate individuals to leave them. This study introduces environments of synergy and dissonance utilising team production functions and utilises them to analyse how team environments vary in their propensity to generate spinoffs. We show that the teams exhibiting synergy are not likely to spawn spinoffs but a new idea from a team member gets implemented only if it is of exceptional quality. The concepts of synergy and dissonance can also be utilised to analyse other phenomena such as mergers and alliances.
\end{abstract}

Keywords: organisational synergy; production function; spinoffs.

Biographical notes: Mili Shrivastava is a Lecturer in Strategy at the Bournemouth University. Her research interests are in firm theory, industrial organisation and economics of strategy and entrepreneurship.

T.V.S. Ramamohan Rao is an Emeritus Professor. His research publications are in the areas of microeconomic theory, industrial organisation, financial economics, and econometrics. 


\section{Introduction}

Teams are an important organisational mechanism in several economic activities. Recent studies suggest that team formation has become a necessity to achieve the requisite diversity of talents for corporate success (Milliken et al, 2003; Jones, 2009). ${ }^{1}$ Furthermore, innovations that require extensive knowledge are by necessity a result of team effort (Wuchty et al., 2007; Jones, 2009). Usually, a team therefore consists of individuals with heterogeneous talents who work together to fulfil a well defined objective. In addition to providing access to knowledge for immediate projects, a team acts as an important source of new ideas. Individuals within the team acquire knowledge sets, offer their expertise to others as required, learn from each other and internalise organisational goals (deVaro and Kurtulus, 2006; Garicano, 2000).

A team exhibits organisational synergies if the expected output from team work exceeds the sum of outputs that the individuals can produce on their own. Synergies are a result of voluntary compliance of team members to organisational goals (Milliken et al., 2003; Cornqvist et al., 2006; Magni et al., 2009). ${ }^{2}$ Team production may also reduce costs in relation to what can be achieved by market coordination. This constitutes another source of organisational synergy.

Realising potential synergies in practice seem to require some preconditions. First, as Garicano and Hubbard (2009) argued, team members prefer autonomy as far as possible. Hence, team members comply and create synergies only if they participate in the decision making process or they know why certain decisions are taken. Second, the willingness to cooperate depends on the perception of equity in sharing gains. As Dessein et al. (2007) pointed out, compensation to team members should depend on their production effort and the time spent on coordination. Third, potential synergies can be realised if every team member offers his best effort to do his specific job and all the team members understand team goals and execute team work efficiently. A team is efficient and stable only when organisational synergies can be achieved. It lacks the fundamental synergy of being a team when it does not produce more output than the sum of individual outputs.

Not all team environments exhibit synergies. Some team environments may experience dissonance and in such cases disadvantages of team production are discernible. For instance, Danzon et al. (2005) noted that there may be organisational dissonance as team size increases. In particular, coordination costs increase as team size increases partly due to the energy that must be utilised to resolve disagreements. Similarly, Wiggins (1995) pointed out that there may be limits to team size depending on the occurrence of organisational dissonance. Teams that have autonomy of decision making tend to emphasise their satisfaction at work while neglecting the viability of the team. In addition, Fulghieri and Hodrick (2006) noted that autonomous individuals may choose activities from which they cannot be displaced rather than choose the most profitable activities for the team. As a result an increase in team size leads to the possibility of free riding by individual members of the team. For following Alchian and Demsetz (1972), Klein et al. (1978) and Rose (2002), it may be noted that benefits of shirking accrue to the individual while the disadvantages and expenses must be borne by everybody in the team.

Team members get new ideas with the accumulation of knowledge and expertise over time team. Such team members should be adequately compensated to retain them in the team. Otherwise, new ideas are another driver of spinoffs in addition to organisational dissonance (Chatterjee and Rossi-Hansberg, 2008). 
Team production functions exhibit the organisation of production in a team and the extent to which team members are independent, or related to each other, within the team. Thus team production environments generate dissonance or synergy depending on the way individuals work together in a team. We show that the lack of synergy in team environments signals possibilities of spinoffs by team members. Individuals of any level of talent may find it advantageous to leave the team and start a firm on their own rather than working in a team exhibiting dissonance. However, there will be no spinoffs if every team member is getting the returns as they would have got working independently.

The study is organised as follows. Section 2 is devoted to the specification of team production functions. Section 3 examines team stability and spinoff generation by analysing the nature of team production functions. Section 4 provides an analysis of how the environment in the pre-spinoff period is linked with the nature of spinoffs that occur. Section 5 examines the role of new ideas in a team environment in spinoff generation and how these ideas determine the occurrence of a spinoff. Section 6 summarises the findings of the study.

\section{Team production}

This section characterises synergy and dissonance using team production functions. ${ }^{3}$ Assume a short run specification that capital equipment is already in place and not substitutable with labour. Owners of capital will be residual claimants of profits generated by the team. However, the team consists of individuals of diverse talents which may be substitutable in varying degrees. It is expected that team members willingly cooperate, comply with team goals and create synergies. For, the possibility of substitution among different talents motivates them to comply with team goals and contribute expected synergies.

Assume that a team comprises of individuals with $\mathrm{n}$ talents. It is reasonable to postulate that there will be a few individuals at the highest level of talent (n) and the largest number of workers will have the lowest talent. Let $x_{j} ; j=1,2, \ldots, n$ denote the number of individuals with talent $\mathrm{j}$. Then, by assumption, $\mathrm{x}_{\mathrm{j}-1}>\mathrm{x}_{\mathrm{j}}$ for all $\mathrm{j}=2,3, \ldots, n$. Further, $\mathrm{x}_{\mathrm{n}}$ $=1$ will be postulated. ${ }^{4}$ The organisational production function can be written as

$$
\begin{aligned}
& y=\left(\sum x_{j}^{\beta}\right)^{\alpha / \beta}, \text { where } \\
& y=\text { output, and } 0<\alpha, \beta<1 .
\end{aligned}
$$

Whatever may be the value of $\beta$ some shirking and free riding is possible leading to lesser output. This can be reflected by the specification of $\alpha_{\beta} .{ }^{5}$ In particular, note that if all $\mathrm{x}_{\mathrm{j}}$ operate independently they produce an output $\mathrm{y}^{*}=\sum \mathrm{x}_{\mathrm{j}}>1$. If they form a team the

resulting output is greater than $y^{*}$ if and only if $\alpha>\beta$. In general, organisational dissonance is signalled whenever $\alpha<\beta$. This is the foundation on which team stability and spinoffs from teams will be analysed further.

Note that the existence of synergies is a property of the entire team. However, the decision to spinoff by an individual of talent $\mathrm{j}$ depends only on his returns. Any individual will leave the team if he expects to receive greater remuneration outside the 
team. The sharing scheme is important in explaining the spinoff process as disagreements within the team may pertain to sharing gains. ${ }^{6}$

Disagreements within the team may also arise when a team member comes up with a new idea. The team may agree to implement the new idea if synergies are expected. However, disagreements between team members may arise due to information asymmetry about the profitability of the new idea. ${ }^{7}$

In sum, spinoffs from a team may be due to the absence of synergies. For, in general, the reduction in output also indicates a decrease in wages. A spinoff may occur even in the presence of synergy if there is a disagreement about sharing output. Differences in the perception of synergies may result in either of the above reasons for a spinoff.

\section{Team formation, stability and spinoffs}

It is necessary to examine the reasons why individuals form teams in the first place before analysing team stability or spinoffs from it. The following proposition sets out the conditions for the formation of teams.

Proposition 1: The emergence of diminishing returns to individual effort and the possibility of creating synergies from team formation are central to its emergence.

Proof: Let individuals of only talent j produce the output to begin with. It is obvious that such an organisation will experience diminishing returns. The output will be

$$
y=x_{j}^{\beta}, \beta<1
$$

Each individual receives a wage

$$
\mathrm{w}_{\mathrm{j}}=\beta \mathrm{x}_{\mathrm{j}}^{\beta-1}
$$

They may realise that they can use their talents more efficiently if they form a team with individuals of another talent $\mathrm{k}$. The emergence of synergies can be represented by the production function

$$
y=\left(x_{j}^{\beta}+x_{k}^{\beta}\right)^{\alpha / \beta} ; \alpha>\beta
$$

The wages paid to an individual of talent $\mathrm{j}$ then becomes

$$
\mathrm{w}_{\mathrm{jt}}=\alpha \mathrm{x}_{\mathrm{j}}{ }_{\left.\mathrm{x}_{\mathrm{j}}+\mathrm{x}_{\mathrm{k}}\right)^{\alpha / \beta-1}}^{\beta}
$$

Observe that $w_{j t}>w_{j}$ whenever $\alpha>\beta$ and $x_{j}, x_{k}>1$. The possibility of deriving such benefits from synergies is at the apex of team formation and its stability in general. ${ }^{8}$

We now analyse team environments that are likely to generate spinoffs. Within this framework, the team and its organisational structure will remain stable or less likely to encourage spinoffs if individuals of various talents receive higher wages (say, in comparison to what they can earn in other team environments). The following propositions outline the stability of team environments.

Proposition 2: Teams that experience organisational synergies are not likely to spawn spinoffs. 
Proof: Recall that $\alpha>\beta$ is the only way to ascertain the existence of organisational synergies. Consider the production function $y=\left(\sum x_{j}\right) ; \alpha>\beta$. The wages paid to a

$\beta \alpha / \beta-1 \quad \beta-1$

worker of talent $\mathrm{j}$ will be $\mathrm{w}_{\mathrm{j}}=\mathrm{a}\left(\sum \mathrm{x}_{\mathrm{j}}\right) \quad \mathrm{x}_{\mathrm{j}} \quad ; \mathrm{j}=1,2, \ldots, \mathrm{n}$. The owner of capital will

receive $p=(1-\alpha) y$. If an individual of talent $j$ contemplates a spinoff he has to form a team of individuals of talent $\mathrm{k}=1,2, \ldots, \mathrm{j}$. Suppose he can assemble such

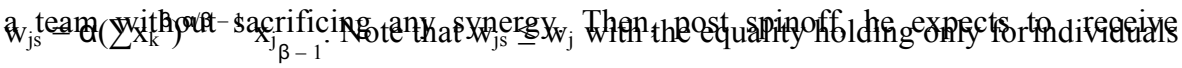

of the highest talent. Thus, it can be inferred that none of the team members will have any motivation to spinoff so long as the team maintains its synergy. This provides an insight into the empirical observation in the spinoff literature that acquisitions and mergers tend to increase the rate of spinoffs (Klepper and Thompson, 2010). For, they may signal difficulties in achieving expected synergies.

Proposition 3: Suppose $\alpha=\beta$ and such teams are formed. They are not likely to spawn spinoffs.

Proof: When $\alpha=\beta$ the production function reduces to $y=\sum x_{j}{ }^{\alpha}$. In such production environments team members will be indifferent between forming a team versus working independently. However, they may work as a team due to the following reasons. First, if each team member needs to share capital equipment (a common resource to the team) it may be efficient for a coordinator to allocate capital to the team members but allow them to function independently. Buenstorf and Fornahl (2006) designate such a property of the production process as modularity. This represents the classic M-form organisation. Second, if they operate independently there may be costs of acquiring capital to produce a marketable product. However, the costs of coordination by market forces may far exceed those within the team. In such a case they prefer to form a team though the payments to individual members of the team are marginal produçts they contribute. When a team is formed wage paid to a worker of talent $\mathrm{j}$ is $\mathrm{w}_{\mathrm{j}}=\alpha_{\mathrm{j}} \quad$. It is independent of the

contribution of others. If an individual of talent $\mathrm{j}$ operates his own team he will receive the same wages. Thus, he has nothing to gain by spinoff essentially due to the increased cost of coordination by the market. In such a case a spinoff will not be advantageous at all. In this context organisational synergies clearly consist of a reduction in the costs of coordination achieved by team formation.

Thus, Proposition 1 suggests that individuals tend to form bigger teams if it is possible to achieve organisational synergies. Propositions 2 and 3 indicate that such teams remain stable so long as organisational synergies persist.

In sum, if a team exhibits organisational dissonance apriori every individual in the team is better off if he spinsoff. Even individuals of low talent may prefer self-employment rather than working in a team riddled with dissonance. In teams exhibiting synergy every team member is better off while working within the team. At best the highest talented individuals may be indifferent between staying in or spinning off unless they can form a team with greater synergy. 


\section{Pre- and post-spinoff organisation}

Baccara and Razin (2007) noted that in addition to the environment of the current team the organisational structure of the new team is important as it determines the spinoff firm's stability and performance. In addition to analysing team environments and their propensity to spawn spinoffs it is equally necessary to investigate how the current team and the new spinoff team environment determines whether there will be a spinoff or not. This section examines how types of team production functions prior to spinoff and post spinoff determine the emergence of spinoffs.

To analyse this it is sufficient to consider a team of three different talented individuals where two of them create synergy and the third member triggers dissonance. The following proposition holds.

Proposition 6: Initial organisational dissonance and synergies after spinoff are necessary to justify a spinoff.

Proof: Assume that $\mathrm{x}_{1}, \mathrm{x}_{2}$, and $\mathrm{x}_{3}$ constitute a team which exhibits organisational dissonance. That is, the team production function is $y=\left(\sum x_{j}^{\beta}\right)^{\alpha / \beta} ; \alpha<\beta$. Will an individual from $\mathrm{x}_{3}$ spinoff? It can be surmised that $\mathrm{x}_{3}$ requires a similar team to carry on production if he decides to spinoff. Hence, wages paid to an individual of talent 3 after spinoff will be such that $\mathrm{w}_{3 \mathrm{~s}}=\mathrm{w}_{3}$. Consequently, individuals of the highest level of talent are not likely to spinoff.

Will an individual afrom $\mathrm{x}_{2}$ spionff? Within the existing team he receives a wage $\mathrm{w}_{2}=\alpha_{\mathrm{x}_{2}}{ }^{\beta-1}\left(\sum \mathrm{x}_{\mathrm{j}}\right)$. Post spinoff he may operate in a team consisting of $\mathrm{x}_{2}$ and $\mathrm{x}_{1}$

only. One possibility is that the smaller team enjoys synergy. In such a case the production function will be $y=\left(x_{1}{ }^{\beta}+x_{2}^{\beta}\right)^{\gamma / \beta} ; \gamma>\beta$. The corresponding $w_{2 s}$ will be $\gamma\left(x_{1}{ }^{\beta}+x_{2}{ }^{\beta}\right)^{\gamma / \beta}$ ${ }^{1}$. It is then possible to have $\mathrm{w}_{2 \mathrm{~s}}>\mathrm{w}_{2}$ if $\gamma>\beta>\alpha$. It follows that $\mathrm{x}_{2}$ gains by spinoff.

Will an individual from $\mathrm{x}_{1}$ spinoff? Let the production function post spinoff be $\mathrm{y}=\mathrm{x}_{1}{ }^{\alpha}$. Note that wages of this group of workers prior to spinoff are $\mathrm{w}_{1}=\alpha \mathrm{x}_{1}{ }^{\beta-1}$

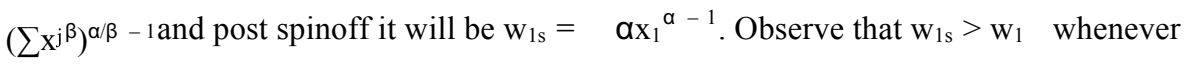
$\mathrm{x}_{1}{ }^{\beta}<\sum \mathrm{x}_{1}{ }^{\beta}$ since $\alpha<\beta$. Hence, even lower talented individuals will spinoff from an environment experiencing dissonance if they are able to achieve synergies in smaller teams. It must be noted that in the post spinoff synergetic environment not only the team member who initiated spinoff but all other members of the team get higher wages. This is perfectly consistent with the experiences of startups in the Silicon Valley.

Assume that we denote the talent to achieve synergy as an entrepreneurial talent such that $\mathrm{a}_{1}<\mathrm{a}_{2}<\mathrm{a}_{3}=1$ where $\mathrm{a}_{\mathrm{j}}$ denotes the talent of individual $\mathrm{j}$. The production function is then modified as $y=a_{1} x_{1}$. In this setting $w_{1 s}<w_{1}$ is possible. That is, lowest talented individuals will not spinoff purely because they do not have the talent to achieve synergy. In retrospect, it should be evident that the possibility of generating synergies post spinoff and/or superior talents of individuals induce a spinoff from a team which cannot create synergies by integration. 


\section{Quality of ideas and spinoffs}

Over time, with the accumulation of knowledge and experience, individuals get new ideas which may be in the form of new techniques for improvements in existing products. If the team member with the new idea is able to convince the existing team that it is profitable and creates synergies then the team may agree to compensate the innovator adequately by offering a share of monopoly rents so that he stays within the team.

There may be disagreements between the innovating team member and the rest of the team if they are not convinced about the economic value of the innovation and/or their ability to implement it within the team. Furthermore there may be disagreements about adequate compensation even if the team agrees to implement the new idea. This may also lead to dissonance. Spinoff by a team member with a new idea is inevitable when the rest of the team members believe that dissonance cannot be reined in even after the introduction of the new innovation. In such a case the quality of the idea is important to determine whether there will be a spinoff or not.

Assume that the team consists of $\mathrm{n}$ talents an $\mathrm{\beta}_{\alpha} \mathrm{\alpha}_{\beta}$ rganisational synergies exist initially. Then, the team production function is $y=\left(\sum x_{j}\right)$. If the current team incorporates the

innovation without sacrificing its synergies the production function can be written as $\mathrm{y}=\tau\left(\sum \mathrm{x}_{\mathrm{j}}^{\beta}\right)^{\alpha / \beta}$, where $\tau$ is the extent of productivity gain from the new idea. The synergies expected from implementing new ideas are least conducive to spinoff. The following proposition holds.

Proposition 7: If organisational dissonance is expected after implementing the new idea in the team a spinoff is worthwhile only if the productivity gains from the quality of new ideas are adequately large.

Proof: Assume that the original team did not agree to incorporate the innovative idea. It motivates the team member to spinoff and form a new team. Hence, let us assume that dissonance is expected in the new spinoff team. The new production function will be $\mathrm{y}=\tau\left(\sum \mathrm{x}_{\mathrm{j}}\right)=\tau \mathrm{y}_{\mathrm{s}} ; \gamma<\beta$. If the individual representing $\mathrm{x}_{\mathrm{n}}=1$ is the source of the idea

and creates a spinoff then the wages to $\mathrm{x}_{\mathrm{n}}$ before and after spinoff are respectively $\mathrm{w}_{\mathrm{n}}=$ $\alpha \mathrm{yx}_{\mathrm{n}}^{\beta-1} / \sum \mathrm{x}_{\mathrm{j}}^{\beta}$ and $\mathrm{w}_{\mathrm{ns}}=\tau \gamma \mathrm{x}_{\mathrm{n}}^{\beta-1} \mathrm{y}_{\mathrm{s}} / \sum \mathrm{x}_{\mathrm{j}}^{\beta} ; \gamma<\alpha$ and $\mathrm{y}_{\mathrm{s}}<\mathrm{y}$. When will $\mathrm{w}_{\mathrm{ns}}<\mathrm{w}_{\mathrm{n}}$ ? Invoking the

result that $\mathrm{y} \tau>\mathrm{y}_{\mathrm{s}}$ we must have $\alpha / \gamma=\tau^{*}>\tau$.

Hence, the individual talent $\mathrm{n}$ will not find it advantageous to spinoff if $\tau<\tau^{*}$. In other words, a spinoff will occur if $\tau$ is large enough even when there is organisational dissonance after spinoff. That is, on the one hand, spinoff may occur if the idea is ofhigh quality even if synergies cannot be achieved post spinoff. On the other hand, if the idea is of good quality and higher synergies are expected post spinoff then it is justifiable. This observation provides an insight into the empirically observed regularity that better firms tend to spawn more spinoffs since only greater synergies outside the team can motivate the individual to move out from a synergetic environment. 


\section{Conclusions}

Teams are formed to create synergies. However, some team environments are synergetic while others exhibit dissonance. An individual contemplates spinoff from a team to generate greater synergies in an alternative team environment when organisational dissonance results in low productivity and low wages in the current team. Thus the possibility of generating greater synergies in an alternative team environment is the source of discontent in the original team and is at the apex of spinoff generation. This study demonstrated that teams which experience dissonance are the least stable and tend to generate spinoffs. An individual of any talent is better off by spinning out than working in a team experiencing dissonance. Teams that experience synergy are less likely to spawn spinoffs. Higher talented individuals are not likely to spinoff unless they expect greater synergies in the new team to overcome the cost of forming the new team. This suggests that teams experiencing synergy, if at all, give rise to more synergetic spinoffs. The spinoffs may be due to new ideas but implementation of a new idea within the existing team is less likely when the existing team experiences synergy unless the new idea is of very good quality. Thus, when a team exhibits synergy, the quality of the new idea plays a very important role in spinoff generation. This provides an insight into the reluctance of better performing firms to pursue new ideas. They do so since they are afraid of losing current synergy.

Throughout this study the possibility of an increase in wages was considered as the major driving force that motivates spinoffs. This may be due to synergies, better quality of ideas and/or superior talents of individuals who contemplate the spinoff. Alternatively, this can be interpreted to mean that the knowledge about the possibility of generating greater synergy in a spinoff will be the source of disagreements of working in the original team.

However, an individual may prefer greater autonomy and dislike the bureaucracy of large firms. Similarly, as Ferrary (2008, p.608) noted, "spinoffs constitute a contract which is symbolically and psychologically motivating because it enables the researcher to identify with his project and to be identified with it through his social and professional milieu." Also see Benz and Frey (2008). They will spinoff even under circumstances where they stand to gain due to the increased wages that they expect due to synergies of team formation. Usually, the spinoff must finance its activities from sources outside the team. In some cases, a spinoff may be based entirely on the possibility that stakeholders are convinced about the greater probability of success of the spinoff team. It is necessary to examine such alternatives within this framework to achieve greater generality.

However, this dissonance and synergy theory can explain a number of insights that have emerged from other theories of spinoffs like the disagreements theory (Klepper and Thompson, 2010), opportunity and necessity theory (Buenstorf, 2009) and ideas theory (Chatterjee and Rossi-Hansberg, 2008). While the sheer variety of causes and types of spinoffs make it difficult to suggest an all inclusive theoretical framework, the generic form of the production function developed in this study can explain several types and instances of spinoff firms in reality. Furthermore, this study is the first to present a rigorous formulation of synergies and dissonance that has potential applications to mergers and alliances. 


\section{Acknowledgements}

We wish to thank Uwe Cantner, Sebastian von Engelhardt, Jagannadha Pawan Tamvada, Sebastian Vergara, Benjamin Volland and participants at Jena Economic Research Workshop for their helpful comments and suggestion. Mili Shrivastava wants to thank members of STICERD at London School of Economics for helpful discussions on teams. We also appreciate the observations of the referees and the editor that improved the presentation considerably. The usual disclaimer applies.

\section{References}

Adams, C.P. (2005) 'Optimal team incentives with CES production', Economics Letters, Vol. 92, No. 1, pp.143-148.

Alchian, A. and Demsetz, H. (1972) 'Production, information costs, and economic organization', American Economic Review, Vol. 62, No. 5,pp.777-795.

Arrow, K.J., Chenery, H.B., Minhas, B.S. and Solow, R.M. (1961) 'Capital labor substitution and economic efficiency', Review of Economics and Statistics, Vol. 43, No. 3, pp.225-250.

Baccara, M. and Razin, R. (2007) 'Bargaining over new ideas: the distribution of rents and the stability of innovative firms', Journal of the European Economic Association, Vol. 5, No. 6, pp.1095-1129.

Beckman, C. (2006) 'The influence of founding team company affiliations on firm behavior', Academy of Management Journal, Vol. 49, No. 4, pp.741-758.

Benz, M. and Frey, B.S. (2008) 'Being independent is a great thing: subjective evaluations of self-employment and hierarchy', Economica, Vol. 75, No. 298, pp.362-383.

Buenstorf, G. (2009) 'Opportunity spinoffs and necessity spinoffs', International Journal of Entrepreneurial Venturing, Vol. 1, No. 1, pp.22-40.

Buenstorf, G. and Fornahl, D. (2009) 'B2C - bubble to cluster: the dot-com boom, spinoff entrepreneurship, and regional agglomeration', Journal of Evolutionary Economics, Vol. 19, No. 3, pp.349-378.

Cassiman, B. and Ueda, M. (2006) 'Optimal project rejection and new firm startups', Management Science, Vol. 52, No. 2, pp.262-275.

Chatterjee, S. and Rossi-Hansberg, E. (2008) 'Spinoffs and the market for ideas' [online] http://www.philadelphiafed.org/research-and-data/publications/working-papers/2008/ wp28-26.pdf (accessed 26 February 2014).

Cornqvist, H., Low, A. and Nilsson, M. (2006) 'Does corporate culture matter for firm policies' [online] http://www.sifr.org/PDFs/sifr-wp48.pdf (accessed 26 February 2014).

Danzon, P., Nicholson, S. and Periara, N. (2005) 'Productivity in pharmaceutical biotechnology R\&D: the role of experience and alliances', Journal of Health Economics, Vol. 24, No. 2, pp.317-339.

Dessein, W., Garicano, L. and Gertner, G. (2007) Organizing for Synergies [online] http://ssrn.com/abstract $=984561$ (accessed 26 February 2014).

deVaro, J. and Kurtulus, F. (2006) 'What types of organizations benefit from team production, and how do they benefit?', Advances in the Economic Analysis of Participatory and LaborManaged Firms, Vol. 9, pp.3-54.

Ferrary, M. (2008) 'Strategic spinoffs: new incentive contract for managing R\&D researchers', Journal of Technology Transfer, Vol. 33, No. 6, pp.600-618.

Fulghieri, P. and Hodrick, L.S. (2006) 'Synergies and internal agency conflicts: the double-edged sword of mergers', Journal of Economics and Management Strategy, Vol. 15, No. 3, pp.549576. 
Garicano, L. (2000) 'Hierarchies and the organization of knowledge production', Journal of Political Economy, Vol. 108, No. 5, pp.874-904.

Garicano, L. and Hubbard, T.N. (2009) 'Specialization, firms and markets: the division of labor within and between law firms', Journal of Law, Economics, and Organization, Vol. 25, No. 2, pp.339-371.

Jones, B.F. (2009) 'The burden of knowledge and the 'death of the renaissance man': is innovation getting harder?', Review of Economic Studies, Vol. 76, No. 1, pp.283-317.

Klein, B., Crawford, R. and Alchian, A. (1978) 'Vertical integration, appropriable rents, and the competitive contracting process', Journal of Law and Economics, Vol. 21, No. 2, pp.297-326.

Klepper, S. and Sleeper, S. (2005) 'Entry by spinoffs', Management Science, Vol. 51, No. 8, pp.1291-1306.

Klepper, S. and Thompson, P. (2010) 'Disagreements and intra-industry spinoffs', International Journal of Industrial Organization, Vol. 28, No. 5, pp.526-538.

Magni, M., Proserpio, L., Hogel, M. and Provera, B. (2009) 'The role of team behavioral integration and cohesion in shaping individual improvisation', Research Policy, Vol. 38, No. 6, pp.1044 1053.

Milliken, F., Bartel, C. and Kurtzberg, T. (2003) 'Diversity and creativity in work groups: a dynamic perspective on the affective and cognitive processes that link diversity and performance', in Paulus, P.B. and Nijstad, B.A. (Eds.): Group Creativity: Innovation Through Collaboration, Oxford University Press, Oxford.

Rose, D. (2002) 'Marginal productivity analysis in teams', Journal of Economic Behavior and Organization, Vol. 48, No. 4,pp.355-363.

Wiggins, S. (1995) 'Entrepreneurial enterprises, endogenous ownership, and the limits to firm size', Economic Inquiry, Vol. 33, No. 1,pp.54-69.

Wuchty, S., Jones, B. and Uzzi, B. (2007) 'The increasing dominance of teams in production of knowledge', Science, Vol. 316, No. 5827,pp.1036-1039.

\section{Notes}

1 There is a fairly general agreement that teams with diverse talents are often more creative compared to homogeneous teams. Similarly, if team members worked at many different companies they bring unique ideas and contacts that encourage innovation. For instance, Beckman (2006) noted that team composition and members' prior affiliations shape new firm behaviour. However, it appears that homogeneous teams manage implementation better while heterogeneous teams are more innovative.

2 Alchian and Demsetz (1972) argued that two or more individuals working together may create synergies. Their example suggests that each of the two individuals may not be in a position to lift heavy equipment from a truck but they can do so working together.

3 It will be assumed that the team is producing only one product. Such an assumption enables us to focus on team formation and the resulting synergies. Some synergies will also be due to an appropriate choice of the product range if the team produces many products. The requisite analysis will be quite similar.

4 It may be argued that individuals from group $\mathrm{j}$ will have a productivity $\mathrm{a}_{\mathrm{j}}$ and that it will not be the same for all $\mathrm{j}$. In such a case replace $\mathrm{x}_{\mathrm{j}}$ by $\mathrm{z}_{\mathrm{j}}=\mathrm{a}_{\mathrm{j}} \mathrm{x}_{\mathrm{j}} . \mathrm{z}_{\mathrm{j}-1}>\mathrm{z}_{\mathrm{j}}$ for all $\mathrm{j}=2,3, \ldots, \mathrm{n}$ can still be maintained without any loss of generality. Another way of justifying the specification is to measure the units of $x_{j}$ in such a way that the productivity of $x_{j}$ is the same for all $j$.

5 In this specification $\alpha$ represents synergies for given $\mathrm{x}_{\mathrm{j}}$. The usual interpretation of economies of scale applies only when all $x_{j}$ change proportionately. However, $\alpha>\beta$ signals an increase in output even if all $\mathrm{x}_{\mathrm{j}}$ do not increase proportionately. Arrow et al. (1961, p.247) acknowledged such ambiguity in the returns to scale interpretation. 
6 Some aspects pertaining to contractual sharing have been examined in Adams (2005), deVaro and Kurtulus (2006) and Dessein et al. (2007).

7 Cassiman and Ueda (2006) suggested that this pattern emerges whenever the original team does not have the organisational capacity to internalise large innovative projects. The possibility of cannibalisation of existing products and the inability to develop new markets add to their decision to reject the implementation of fairly large innovative ideas (e.g., Klepperand Sleeper, 2005).

8 Note that $\alpha<1$ is a distinct possibility. Hence, there is an acknowledgement that bigger teams may also experience diminishing returns. As a result, the search for synergies through team expansion continues. 